\title{
Project Management: A Critical Area of Study for Engineering \& Engineering Technology Students
}

\author{
Jule Dee Scarborough \\ Northern Illinois University
}

Introduction

Project management has become a critical area of study. Many industrial organizations are restructuring into project teams. Knowledge and skills in industrial project management and interdisciplinary teaming are becoming more and more important to engineers and technologists. "Project management is an excellent management process for managing unique jobs or activities with a clearly defined scope, schedule, and cost . . into a work package"(Reeder, 1995, p. 29). When combining a project with a team, project management becomes team management. Kezsbom (1995) defined this as "a highly collective, integrated process that requires the application of a variety of participative approaches to blend all the technical and organizational components of the project into a cohesive whole" (p. 39) .

Specific types of project teams are evolving, such as employee/customer project- management teams. The Australians first conceptualized this process where the management structure established an organizational climate to promote all aspects of productivity. The employee/customer teams "are groups of company employees, customers, and management personnel who are motivated to discuss and work together and become involved in a participative problem-solving process" (Ross, 1993, p. 3). Others, LaFleur (1996) for example, discuss necessary skills for project team members and managers or leaders. The decision-making process is critical and organizations must determine who the decision makers are up-front. In addition, it is important for project teams to fully understand the project process itself, namely, thought, study, research, planning, and implementation. The communication process is also critical. Scheduling is one of the most difficult tasks in project management, especially of scarce resources over time, whether human or machine resources, etc. (Herroelen \& Demeulemeester, 1996). And, finally, building successful cross-functional teams takes time, dedication, and patience.

There is usually substantial resistance to taking the time to build integrated project teams and plans. The impact of limited resources, global competition, and time pressures often leads organizations into thinking there is not enough time for group planning and team development; however, in reality, they do not have the time not to. It is now impossible to produce a product or service without the assistance of many different types of individuals. One individual can no longer accomplish a total effort, therefore, it is imperative that group planning and team development occur (Kezsbom, 1995). This, in turn, requires that congruence or alignment 
between the internal and external be achieved. The internal reflects what is thought and felt and the external reflects what is said and how it is said. "In order to operate congruently in the world, you need to take into account three general factors: self (the internal world), other (the immediate external world of people), and context (the larger external world of things, structures, processes, laws, and cultures)" (McLendon \& Weinberg, 1996, p.34). This cannot usually occur without individual and team development.

High performance teams achieve both individual and team congruence. Achieving congruence begins with awareness, continues to acceptance, authorship, articulation, and finally is achieved with articulation (McLendon \& Weinberg, 1996).

Engineers and technologists are now required to work well beyond their technical world in content and context; in addition, they are now often asked to work in multicultural teams and to lead or participate in projects. This requires an additional tool kit, one that includes tools to work with people, tools in management, and techniques for integrating across disciplines and cultures. Therefore, it seems plausible that project management has become its own integrated discipline and has achieved the status of a career path.

Duarte, Lewis, Hoffman, and Crossman (1995) studied career development for individuals in engineering and engineering management over 30 years. They indicate that the project management workforce

can be differentiated from other management positions in at least three ways. First, the individuals that perform in these roles typically have engineering or other technical backgrounds and have not been trained as managers. Second, these individuals are primarily involved in guiding cost, schedule and other administrative functions. They are not directly involved, as an engineering manager would be, in the day to day technical decisions about the design, development and test of engineering systems, nor are they in charge of a functional area that provides an ongoing product or service. Rather, they manage the overall cost, schedule and technical aspects of an engineering project that has a definitive beginning and ending. (pp. 149-150)

The NASA study focused on the development of a career model for managers of projects. They concluded that all organizations which are managing large, technically complex projects and which are facing increased technological complexity, international partnerships, limited resources, and smaller workforces share the need to carefully develop project managers. Thus, they identify project management job requirements as:

Organizational Knowledge

Technical Management

Program Control and Project Life Cycle

Individual and Team Development

Risk Management and Safety

\section{Logistics}

Contracting/Acquisition

Inter-Agency, Business, \& International Relations

As a result of the growing need for engineers and technologists to become familiar with project 
management, Northern Illinois University's Department of Technology in the College of Engineering \& Engineering Technology developed a course in project management as a prerequisite course to the senior design capstone course. In addition, to better address the ABET 2000 and new TAC ABET criteria, the professor for that course is leading an interdisciplinary team to develop an interdisciplinary, college-wide, project management course to serve as a prerequisite to an interdisciplinary, college-wide, senior design capstone course. The departments involved are Electrical Engineering, Mechanical Engineering, and Industrial Engineering, and the Department of Technology (which offers degrees in manufacturing and electrical engineering technology and industrial technology).

The Undergraduate Project Management Course

Although the Department of Technology offers a project management course for both undergraduate and graduate students, the following course is a three-credit-hour prerequisite to the undergraduate senior design capstone course to better prepare students for the senior design experience. The senior design experience is a required team experience; thus, the project management prerequisite prepares students to work in teams as well as in project management techniques through lectures, hands-on activities, case studies, and a mini-project. The graduate course is offered for full-time employed engineers and managers and will not be discussed here.

\section{Course Topics}

The course topics for the undergraduate project management are the following:

Projects \& Change Management Planning and Developing a Project Plan

Project Management \& Management International \& Cross-Cultural Projects

Strategies

Project \& Organizational Structure

Quality in Project Management

Team Building \& Team Work

Power, Influence, \& Leadership

Budgets, Controlling Costs,

\& Scheduling

Work Break-Down Structures

Procurement \& Contracting

Project Success Factors--SWOT
Project, Team, \& Conflict Assessment

Project Documentation

Project Murder vs. Project Termination--

Learning from a Project Appropriately

Project Management Applications--Types

Project Management Applications--Types

Risk Management \& Contingency Planning

Resource Planning \& Allocations

Time/Cost Tradeoffs

Project Design \& Prototyping

\section{Course Activities}

The course activities in the undergraduate project management course are as follows:

Establish teams

Determine mini-project concept
Develop team operational policies \& procedures

Individual \& team logs (journals) 
Develop team and project charter

Develop project, peer, team, \& conflict assessment inventories

Develop portfolio format

Design project \& build prototype

Develop team skills bank

Train to use Problem-Solving Techniques

Project management \& team videos
Project management software workshops

Diversity workshop

Ongoing assessment of project, team, peers, \& conflict

Ongoing team issues, discussions, \& resolutions based upon instructor's reading of individual

$\&$ team journals-Conflict Management

Individual and Team plans

\section{Course Requirements}

This course engages students in both authentic and traditional assessment. Each activity listed above serves as assessment, and the completion of each course requirement listed below serves as the final evaluation in particular areas.

Literature search for articles on projects, project teams, project management, issues, problems, and solutions. Issues, problems, and solutions paper.

Case studies in two industrial organizations where projects are operating--report.

Project management software test--must achieve $100 \%$ or retake.

Individual and Team project plan--required format provided of 40 elements.

Mini-team technical project--fully operational prototype.

Project and team portfolio.

Project and team presentation--professional dress \& visuals required.

Midterm exam--project management and project teams.

Final exam--commonalities and differences between different types of projects.

The project and team portfolio serves not only to document the project product but the team process as well. It presents not only the team's operational policies and procedures, but includes records of team problems, issues, resolutions, growth, assessment, decision-making strategies and the results of those decisions, changes in plans, all prototype and technical documentation, assessments, evaluations, project monitoring, etc. Each student develops his or her own individual project plan first. Once evaluated, students then develop the team plan for the project. Thus, all team members bring their own plans to the table after the professor's comments and grading; they use the feedback to develop a better team plan. This process serves to help students process how to make their own plans better through the development of the team plan. In some cases, individual students and teams redo assignments not accomplished at an acceptable level (that is, an A or B grade) based upon specific grading rubrics.

\section{Interdisciplinary Approach to Project Management}

As mentioned above, an interdisciplinary team (IT) from four departments met to conceptualize an interdisciplinary project management and team prerequisite course sequence, and senior design capstone course. The IT determined that there would be an interdisciplinary teaching faculty team, and the goal would be to have at least one student from each department make up 
each interdisciplinary student team. When numbers would not allow that mix, at least three departments would be represented on each student team. In addition, it could be possible that two Technology students would be on a college team, because of the number of different programs, that is, manufacturing and electrical engineering technology and industrial technology.

Course Content

The IT conceptualized several course strategies, one based on the Technology model discussed above, a three-credit-hour lab course prerequisite to the senior design course. However, when discussing the ABET 2000 criteria, assessment strategies, and how best to develop knowledge and skills in students over time, they determined that possibly three, one-credit-hour courses would best serve the goals of having students build and use knowledge and skills throughout their program and the development of better assessment strategies. Therefore, the following has been conceptualized as a preferred approach to submit to the college for consideration:

Course I - Interdisciplinary Project Teams (1 credit hour)

Content for this course is as follows:

Introduction to project management \& portfolios

Interdisciplinary teaming

Interpersonal skills critical to functional team members

Group process, team stages, etc.

Project leader, team members, roles, \& responsibilities

Organizational structure, team charter \& map

Conflict resolution

Assessment of project, team, peers, \& conflict

Communication skills--organizing communication

Technical written communications--types \& format

Oral presentation skills

Problem solving

Project success factors

Introduction to design

Course II - Industrial Project Management (1 credit hour)

Content for this course is as follows:

Project management

Selecting and prioritizing projects

Planning-goals, objectives, \& framework

Work breakdown structure

Resource planning \& allocation

Procurement \& contracting

Budgeting \& cost control

Scheduling

Risk management

Contingency planning

Time/cost tradeoffs 
Project success factors-SWOT analysis

Introduction to concurrent engineering

Plan/proposal writing

Course III - Interdisciplinary Project Design and Organization (1 credit hour)

Content for this course is as follows:

Research resources, standards

Consultant/client relationship

Team operational policies \& procedures

Patents, legal liability

Ethics

Scientific investigation

Data collection

Problem-solving tools

Multi-criterion decision making \& analysis

Concurrent engineering

Plan/proposal writing

Team mini-project-initial work on design project for capstone project

The philosophy and operational strategies for this sequence as a prerequisite are:

1. The students will have multiple team experiences in Courses I \& II.

2. The teams established in Course III will continue as teams in the Senior Design Capstone Course.

3. The students will initiate their senior design project in Course III and continue in the capstone course. Some work on design, preliminary data collection, and procurement will be accomplished as the mini-project in this course.

4. Each course meets one hour each week for content delivery; then a team lab time will be required so that the teams can do their assignments together.

Although the course described above is an excellent approach, several of the advantages to this approach to the one currently in process seem to be:

1. Students will have more team experiences to develop team skills over time, and they will gain more experience with a more diverse set of individual team members because of the added opportunities for team activities.

2. Design will be introduced earlier and reinforced several times before the actual senior capstone design experience.

3. Students will build portfolios and will be assessed over longer periods of time; they will also be expected to transfer learning directly from one course to another more formally.

4. Students will work with an interdisciplinary faculty lead team.

Summary

The first strategy (Technology model) described above is somewhat new to undergraduate 
programs in engineering, engineering technology, and industrial technology. A review of the engineering and engineering technology literature revealed that most programs do not incorporate most of the project management content into their programs and that most universities do not yet require formal team training. There has, however, been some movement towards incorporating teaming content into existing classes. Some of the Coalitions funded by the National Science Foundation have restructured their curriculum and instructional delivery to include such content.

The approach engages students and student teams in innovative activities using both traditional and authentic assessment strategies, including portfolio development. The second approach, however, seems to have several advantages over the first one. It builds students knowledge and skills on project management, teaming, and design over time, and they develop individual portfolios. Students also work with an interdisciplinary faculty team throughout the three-course project management sequence and then again in the senior design capstone course. Not only will they work with students from other disciplines, but multi-tasking will be required as well. The IT feels that this is one of their next steps to continuous improvement in response to the ABET 2000 criteria.

\section{References}

Agogino, A., Jenison, R., Muramatsu, B., Dalonji, G., Regan, T., Zorowski, C., Coleman, R., Demel, J., Beaufait, F., Evans, D., Brody, H., Williams, R. "A progress Report - The Engineering Education Coalitions.” ASEE Prism. Sept. 1996.

Duarte, D., Lewis A., Hoffman, E. J., \& Crossman, D. (1995). A career development model for project management workforces. Journal of Career Development, 22 (2), 149-164.

Herroelen, W. S., \& Demeulemeester, E. L. (1996). Project management and scheduling. European Journal of Operational Research, 90, 197-199.

Kezsbom, D. S. (1995). Making a team work: Techniques for building successful crossfunctional teams. Industrial Engineering, 39-41.

LaFleur, R. (1996). Decision making: The key to successful project management. IEEE Software, 33-42.

McLendon, J., \& Weinberg, G. M. (1996, July). Beyond blaming: Congruence in large systems development projects. IEEE Software, 33-42.

Reeder, T. J. (1995). Take a flexible approach. Industrial Engineering, 29-35.

Ross, D. (1993). Employee/Customer project management teams. Journal of Industrial Technology, 9-11. 